\title{
DESIGN OF RECTANGULAR-SHAPED MICROSTRIP PATCH ANTENNAS FOR MILLIMETER WAVE BANDS
}

\author{
RaWAZ Hussain ABdUllah ${ }^{1}$ and KaWAN FAiQ AHMED \\ ${ }^{1}$ Technical College of Engineering, Sulaimani Polytechnic University, Kurdistan Region-Iraq
}

(Accepted for Publication: December 8, 2020)

\begin{abstract}
This study presents the design and simulation of two separate rectangular shaped microstrip patch antennas to operate at $38 \mathrm{GHz}$ and $50 \mathrm{GHz}$ millimeter wave (mmWave) bands, using high-frequency structure simulator (HFSS) software package. The work mainly underlines the importance of utilizing a dialectic substrate from ROGRES Corporation. The substrate is used in the design of the proposed antennas, and is made up of hydrocarbon ceramic laminates, known as the RO4350B. The influence of the dielectric material has been studied on the performance of the antennas, like return loss, voltage standing wave ratio (VSWR), antenna bandwidth, antenna gain, and radiation pattern. The obtained $38 \mathrm{GHz}$ antenna has about $8.06 \mathrm{dBi}$ of gain and a $4.01 \mathrm{GHz}$ of bandwidth with a return loss of less than -10dB from $35.23 \mathrm{GHz}$ to $39.24 \mathrm{GHz}$. On the other hand, the $50 \mathrm{GHz}$ antenna provides a $5.1 \mathrm{dBi}$ of gain with much higher bandwidth (up to $7.2864 \mathrm{GHz}$ ) starting from $47.1106 \mathrm{GHz}$ to $54.397 \mathrm{GHz}$. Beside these remarkable features, the thickness of the selected substrate is $0.762 \mathrm{~mm}$. Both antennas might be used in future 5G wireless communication systems and short-range systems such as machine-to-machine (M2M) and device-to-device (D2D) to fulfill the necessities of wide-bandwidth, high-gain, low-weight, cheap, and easy fabrication.
\end{abstract}

KEYWORDS: Microstrip patch antenna; high-frequency structure simulator (HFSS); millimeter wave (mmWave); dielectric substrate.

\section{INTRODUCTION}

M illimeter wave bands starting from 3 $\mathrm{GHz}$ up to $300 \mathrm{GHz}$ are proposed to be used in the next generation $5 \mathrm{G}$ wireless systems, since it will provide much higher bandwidth in comparison to the current existing systems and as a result it can enhance the transmission data rate. With the increase in bandwidth, the system capacity will also be increased, while the latency will be reduced, which give rise to better internet based access and applications like real time streaming for individual users especially in densely populated areas (Zhouyue \& Farooq, 2011; Akhil \& Rakesh, 2015). Generally microstrip antennas are commonly used in rawaz.abdullah@spu.edu.iq; contemporary wireless systems due to their low-profile, low cost, easily fabricated, and portability (Balanis, 2005; Kraus \& Marhefka, 2002; Behera \& Barad, 2015),. Moreover, some unique characteristics of antennas are required such as high-gain and wide-bandwidth, and proper radiation features for specific applications in modern communication systems (Mishra, Singh, Singh, Singh, \& Singh, 2018). Because of their fantastic properties, many efforts have been done on the analysis, design, and implementations of microstrip antennas.

A simple design of Ku-band microstrip patch antenna, which underlies the mmWave bands, has been proposed in (Bhadouria \& Kumar, 2014). A number of U shaped and semi U shaped kawan.ahmed@spu.edu.iq ${ }^{1}$ Corresponding author: Technical College of Engineering, Sulaimani Polytechnic University, Kurdistan Region, Iraq 
slots on patch are introduced to improve the return loss and bandwidth of the proposed antenna, thereby; a bandwidth of $1.24 \mathrm{GHz}$ is achieved in the range of (15.27-16.51) GHz, and a VSWR of 1.1 is observed at resonant frequency. The FR-4 dielectric substrate with a thickness of $1.07 \mathrm{~mm}$ and dielectric constant of 4.9 is used. In (Haraz, Ashraf, \& Alshebeili, 2015), three-element single-band printed inverted F-antenna is designed on air substrate of thickness of $0.3214 \mathrm{~mm}$ that operates in the 28 $\mathrm{GHz} \mathrm{mm}$-Wave band for the future $5 \mathrm{G}$ wireless communication systems. The corresponding each element gain is $6.06,5.18$, and $5.50 \mathrm{dBi}$, $\mathrm{GHz}$ which provides a bandwidth of $810 \mathrm{MHz}$. A design and simulation of $28 \mathrm{GHz}$ and $38 \mathrm{GHz}$ dual-band millimeter wave antenna with circular polarization for $5 \mathrm{G}$ systems has been presented in (Aliakbari, Abdipour, Mirzavand, Costanzo, \& Mousavi, 2016). The antenna is practically implemented on a $0.254 \mathrm{~mm}$ RT/Duroid 5880 substrate with a dielectric constant of 2.2. A maximum gain of $4 \mathrm{dBi}$ with $850 \mathrm{MHz}$ of bandwidth (from $29.25 \mathrm{GHz}$ to $30.1 \mathrm{GHz}$ ) is observed at the first band. Similarly, a maximum gain of $4.5 \mathrm{dBi}$ with $750 \mathrm{MHz}$ of bandwidth (from $36.25 \mathrm{GHz}$ to $37 \mathrm{GHz}$ ) is measured at the higher band. It is obvious form the results, that some shifts in the desired frequency of operation are observed during the practical measurements. The study conducted in (Wang, Mu, Wang, Safavi-Naeini, \& Liu, 2017) four-pairs of microstrip multiple-input multiple-output (MIMO) antennas have been designed. The dielectric substrate RT/duroid5880 is selected with a height of $0.5 \mathrm{~mm}$ and relative dielectric constant of 2.2. At first, a single patch element is designed and simulated using HFSS, based on the results the operation frequency rages from $33.88 \mathrm{GHz}$ to $36.12 \mathrm{GHz}$, which provides a 2.24 $\mathrm{GHz}$ of bandwidth and also a gain of $7.93 \mathrm{dBi}$ is obtained. Then, with the aid of eight-element microstrip Taylor antenna array with rawaz.abdullah@spu.edu.iq; and the operating frequency was (27.73-to-28.54)

series-feeding a reduction of sidelobs and increment of bandwidth $(3.85 \mathrm{GHz})$ are obtained. The center frequency of the designed antenna array is $35 \mathrm{GHz}$ with $10 \mathrm{dBi}$ of gain. Another recent study (Rahayu, Fitria, Hakiki, \& Kurniawan, 2018) proposed a dual-band 8-element based array antenna for 5G applications. The elements formed in a 2 by 4 square configuration to operate in $28 \mathrm{GHz}$ and $38 \mathrm{GHz}$ mmWave bands. The $0.254 \mathrm{~mm}$ RT/Duroid 5880 substrate with a dielectric constant of 2.2 is used. Each single element is fed with a microstrip line to operate in the dual bands, a bandwidth of $1.219 \mathrm{GHz}$ and $1.42 \mathrm{GHz}$ are obtained at the $28 \mathrm{GHz}$ and $38 \mathrm{GHz}$ center frequencies, respectively. The maximum achievable gain at each band is $6.934 \mathrm{dBi}$ and $7.833 \mathrm{dBi}$, respectively. The 8 elements are connected to configure a $2 \times 4$ phased array; in this case a higher gain of $15.9 \mathrm{dBi}$ at $28 \mathrm{GHz}$ and $16.7 \mathrm{dBi}$ at $38 \mathrm{GHz}$ are obtained using waveguide port as feeder.

In this work, an attractive design of a microstrip antenna has been proposed and analyzed by applying the RO4350B substrate with a thickness of $0.762 \mathrm{~mm}$. The dielectric substrate consists of hydrocarbon ceramic laminates which is used in the design of two different single-microstrip patch antennas to operate in the $38 \mathrm{GHz}$ and $50 \mathrm{GHz}$ mmWave bands. The chosen substrate has the advantage of less weight, smaller size, and less dielectric loss because of its thin height or thickness. In spite of these interesting points, the designed antennas have satisfactory results in bandwidth, gain and VSWR and almost the same or even outperforms compared to the previous related works. Following this introductory part, the rest of the paper is organized as follows: section 2 presents the initial design and optimized parameters of the proposed antennas, and Section 3 covers the simulation results of the designed antennas with comparison with some related works. Finally, the summary of the paper are presented in section 4 . kawan.ahmed@spu.edu.iq

${ }^{1}$ Corresponding author: Technical College of Engineering, Sulaimani Polytechnic University,

Kurdistan Region, Iraq 


\section{ANTENNA DESIGN}

Patch antennas are made up of three layers which are a rectangular ground plane at the bottom, a dielectric substrate in the middle, and the patch on the top. Both of the ground and the patch layers are made of conductors such as copper. Both of the dielectric material and the ground plane having the same dimensions. While many patch antenna shapes has been implemented and studied, rectangular and circular configurations are the most preferred in practice, because of their incredible radiation characteristics (Ahmed, Abdullah, \& Abdalla, 2017; Kraus \& Marhefka, 2002). The schematic diagram of the proposed antenna as well as the design parameters are illustrated in Figure 1.

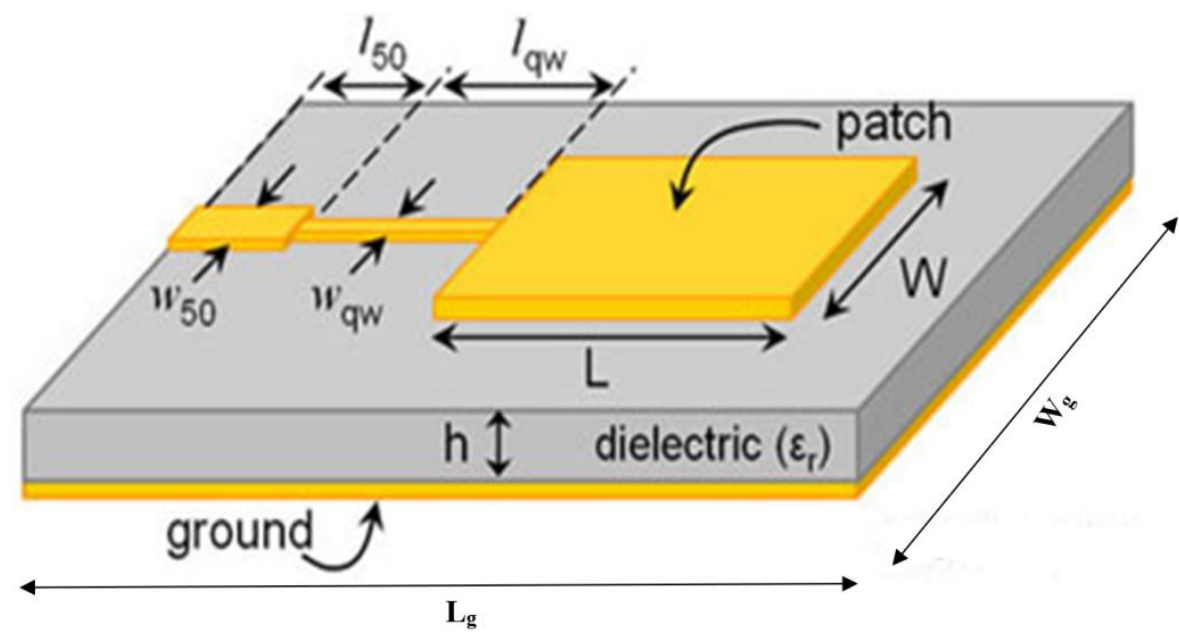

Fig. (1): Schematic diagram of the proposed antenna

Dimensions of the antenna closely related to the operating frequency and the type of the dielectric substrate. The following equations are used to compute the dimensions (width and length) of a rectangular shaped patch antenna (Balanis, 2005):

$$
\begin{aligned}
& W=\frac{1}{2 f_{o} \sqrt{\varepsilon_{o} \mu_{o}}} \sqrt{\frac{2}{\varepsilon_{r}+1}} \\
& \varepsilon_{r_{e f f}}=\frac{\varepsilon_{r}+1}{2}+\frac{\varepsilon_{r}-1}{2} \sqrt{1+12 \frac{h}{W}} \\
& L=L_{e f f}-0.824 h \frac{\left(\varepsilon_{r_{e f f}}+0.3\right)\left(\frac{W}{h}+0.264\right)}{\left(\varepsilon_{r_{e f f}}-0.258\right)\left(\frac{W}{h}+0.8\right)} \\
& L_{e f f}=\frac{1}{2 f_{o} \sqrt{\varepsilon_{r e f f}} \sqrt{\varepsilon_{o} \mu_{o}}} \\
& W_{g}=W+6 h \\
& L_{g}=L+6 h
\end{aligned}
$$

rawaz.abdullah@spu.edu.iq; kawan.ahmed@spu.edu.iq ${ }^{1}$ Corresponding author: Technical College of Engineering, Sulaimani Polytechnic University, 
Where,

$W:$ is the patch width, and $L$ is the length of the patch.

$f_{o}$ : is the resonant frequency

$\frac{1}{\sqrt{\varepsilon_{o} \mu_{o}}}$ : is the speed of light

$\varepsilon_{r}$ : is the dielectric constant, and $\varepsilon_{\mathrm{r}_{\mathrm{eff}}}$ is the effective dielectric constant

$\mathrm{h}$ : is the width or height of the dielectric substrate

$L_{e f f}:$ is the effective patch length

$W_{g}$ : is the width of ground plane, and $L_{g}$ : is the length of the ground plane

Firstly, the initial or approximate dimensions of each antenna are computed using the design equations given in (1) to (6). The first antenna operates at $38 \mathrm{GHz}$ and the other is designed to operate at $50 \mathrm{GHz}$. The RO4350B is chosen to be used as the substrate having a thickness of $0.762 \mathrm{~mm}$ and a dielectric constant of 3.66. The designed antennas have been simulated using high-frequency structure simulator (HFSS), version 13.0.0. During the simulation process, the initial computations of the dimensions of each designed antennas are modified to acquire optimum performance in terms of the radiation patterns, VSWR, bandwidth, and antenna gain. The optimized design parameters for the proposed antennas are given in Table 1. Among many different feeding techniques, in this study the feed line method is chosen to be used for feeding the antennas.

Table (1): Parameters for the proposed antennas

\begin{tabular}{lll}
\hline & $38 \mathrm{GHz}$ Design & $\mathbf{5 0 ~ G H z ~ D e s i g n ~}$ \\
\hline Operating frequency, $\mathrm{f}_{\mathrm{o}}$ & $38 \mathrm{GHz}$ & $50 \mathrm{GHz}$ \\
\hline Substrate height, $h$ & $0.762 \mathrm{~mm}$ & $0.762 \mathrm{~mm}$ \\
\hline dielectric constant, $\varepsilon_{r}$ & 3.66 & 3.66 \\
\hline Patch length, $L$ & $1.64 \mathrm{~mm}$ & $1 \mathrm{~mm}$ \\
\hline Patch width, $W$ & $2.59 \mathrm{~mm}$ & $1.8 \mathrm{~mm}$ \\
\hline Substrate length, $L_{g}$ & $8.37 \mathrm{~mm}$ & $6.23 \mathrm{~mm}$ \\
\hline Substrate width, $W_{g}$ & $9.05 \mathrm{~mm}$ & $5.8 \mathrm{~mm}$ \\
\hline$W_{q w}$ & $0.466 \mathrm{~mm}$ & $0.6 \mathrm{~mm}$ \\
\hline$l_{q w}$ & $1.219 \mathrm{~mm}$ & $0.926 \mathrm{~mm}$ \\
\hline$l_{50}$ & $2.1 \mathrm{~mm}$ & $1.62 \mathrm{~mm}$ \\
\hline$W_{50}$ & $2.1 \mathrm{~mm}$ & $1.4 \mathrm{~mm}$ \\
\hline
\end{tabular}

\section{SIMULATION RESULTS}

In this section, the performances of the proposed antennas are investigated by measurements of the obtained radiation patterns, realized gains, return loss, and VSWR. Several results from other related works are also presented in for the sake of comparison, such as antenna bandwidth, gain, substrate type with its thickness, and antenna configuration.

\subsection{Results of the $38 \mathrm{GHz}$ Antenna}

The simulation of the radiation pattern or the far-field directivity of the designed antenna at 38 $\mathrm{GHz}$ is illustrated in Figure 2. It can be noticed that the simulated antenna mostly radiates in the direction of the observer which is the vertical direction. This agrees with the theoretical radiation pattern for these types of antennas. The antenna has a gain of $8.06 \mathrm{dBi}$ in the direction of the observer. 


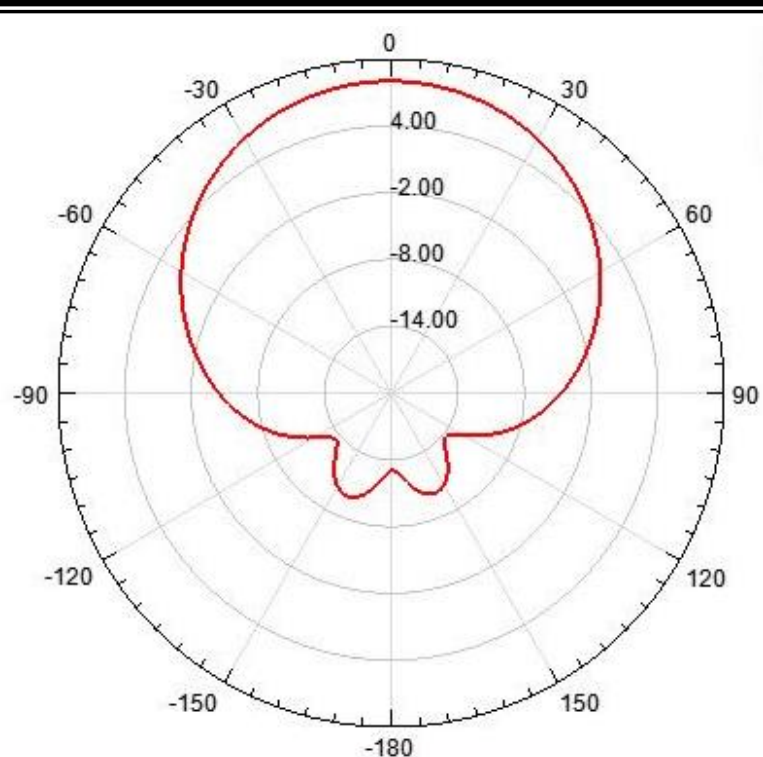

(a)

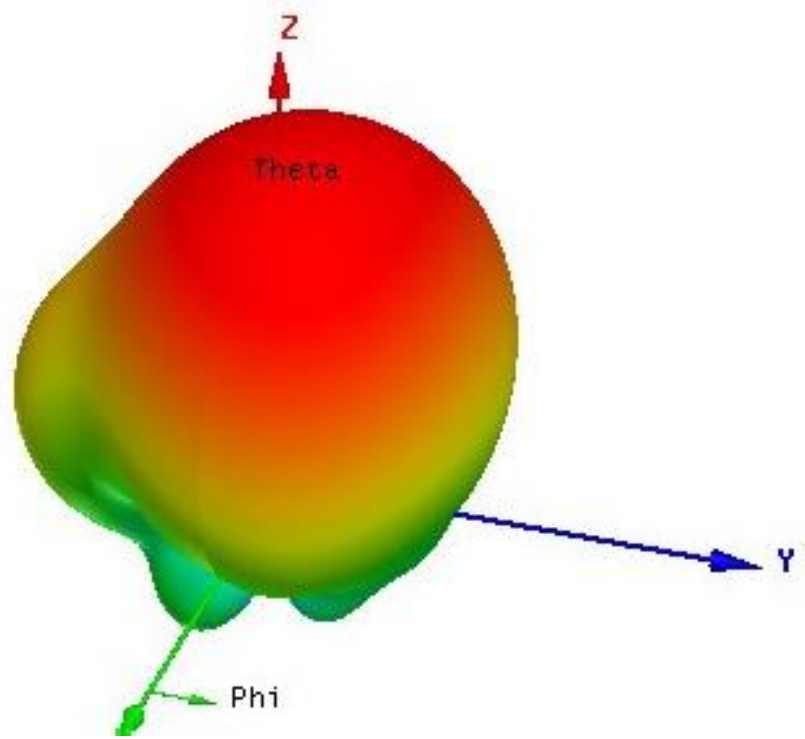

(b)

Fig. (2): Radiation pattern of the $38 \mathrm{GHz}$ antenna (a); (a) 2D pattern, (b) 3D pattern.

The obtained return loss as a function of frequency for the $38 \mathrm{GHz}$ antenna is shown in Figure 3. The return loss of the antenna is $-23.47 \mathrm{~dB}$ at $37.14 \mathrm{GHz}$. It can be observed that, the actual acquired bandwidth, which is computed with the intersection of the curve with
$-10 \mathrm{~dB}$ of the return loss, is ranges from nearly $35.23 \mathrm{GHz}$ to $39.24 \mathrm{GHz}$. Therefore, bandwidth of the antenna is about $4.01 \mathrm{GHz}$. Therefore, the antenna bandwidth is $10.55 \%$ of the center frequency.

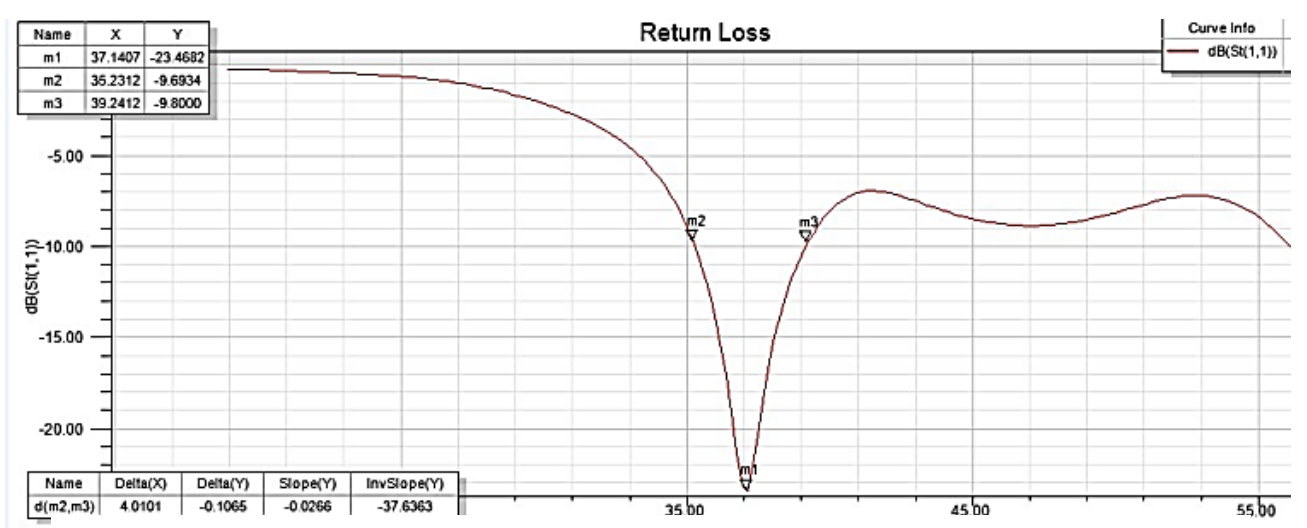

Fig. (3): Return loss versus frequency of the proposed $38 \mathrm{GHz}$ antenna

As it can be depicted in Figure 4, the VSWR of the designed patch antenna approaches to 1.437 at $38.0955 \mathrm{GHz}$ which shows that the antenna well operates in the frequency band of interest.

rawaz.abdullah@spu.edu.iq; kawan.ahmed@spu.edu.iq ${ }^{1}$ Corresponding author: Technical College of Engineering, Sulaimani Polytechnic University, 


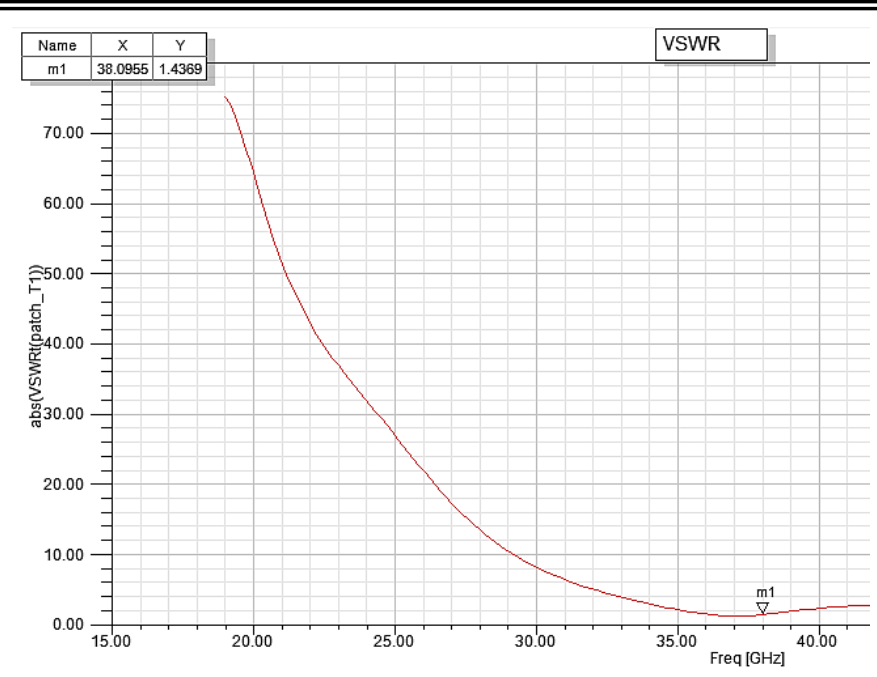

Fig. (4): VSWR versus frequency of the designed $38 \mathrm{GHz}$ antenna

\subsection{Results of the $50 \mathrm{GHz}$ Antenna}

In a similar way as demonstrated in the previous section, the $2 \mathrm{D}$ and $3 \mathrm{D}$ radiation patterns for the proposed $50 \mathrm{GHz}$ antenna are shown in Figure 5. Likewise, as the previously stated, the directivity of the designed patch is in the vertical direction. For this case, the antenna

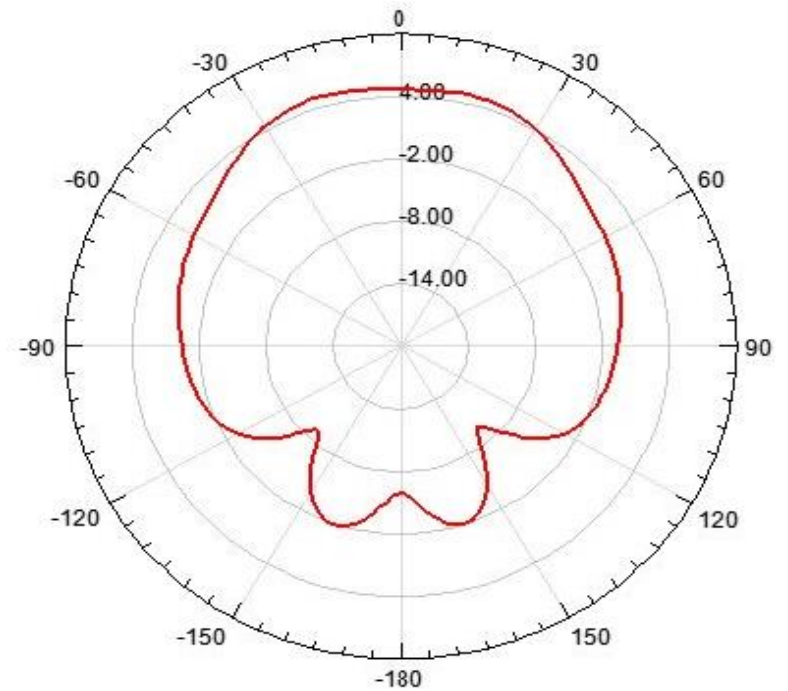

(a) gain is $5.1 \mathrm{dBi}$, which means a penalty of less than $3 \mathrm{~dB}$ of gain can be noticed compared to the $38 \mathrm{GHz}$ design. Unfortunately, the $50 \mathrm{GHz}$ antenna has wider sidelobs with slightly higher power content in the two minor-lobes in comparison to the $30 \mathrm{GHz}$ design.

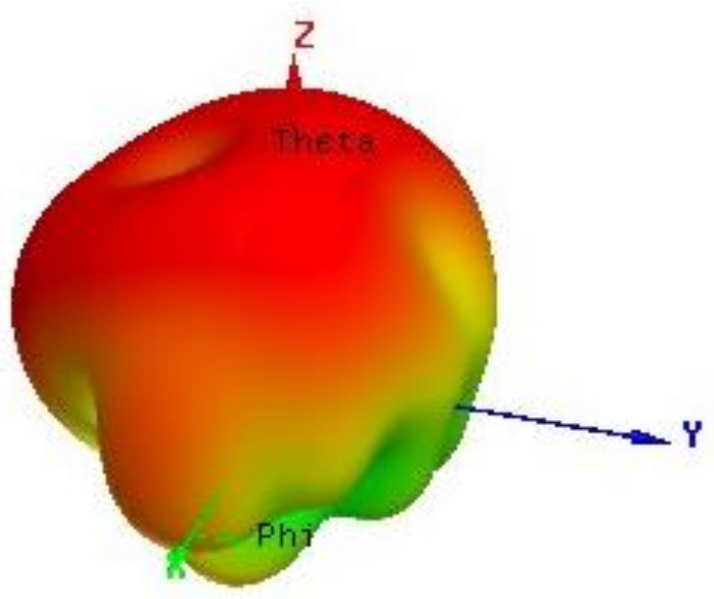

(b)

Fig. (5): Radiation pattern of the $50 \mathrm{GHz}$ antenna (a); (a) 2D pattern, (b) 3D pattern

As it can be noticed in Figure 6; the return loss of the patch is $-30.48 \mathrm{~dB}$ at $50.377 \mathrm{GHz}$, and the frequency of operation is in the range of $47.1106 \mathrm{GHz}$ to $54.3970 \mathrm{GHz}$. The antenna bandwidth is $7.2864 \mathrm{GHz}$, which is higher than the bandwidth of the $38 \mathrm{GHz}$ antenna. In this rawaz.abdullah@spu.edu.iq; case, the antenna bandwidth is around $14.573 \%$ of the resonant frequency.

As illustrated in Figure 7, the VSWR of the $50 \mathrm{GHz}$ antenna is about 1.064 at $50.1256 \mathrm{GHz}$, which is quite comparable or consistent to the ideal value of VSWR.

kawan.ahmed@spu.edu.iq

${ }^{1}$ Corresponding author: Technical College of Engineering, Sulaimani Polytechnic University, Kurdistan Region, Iraq 


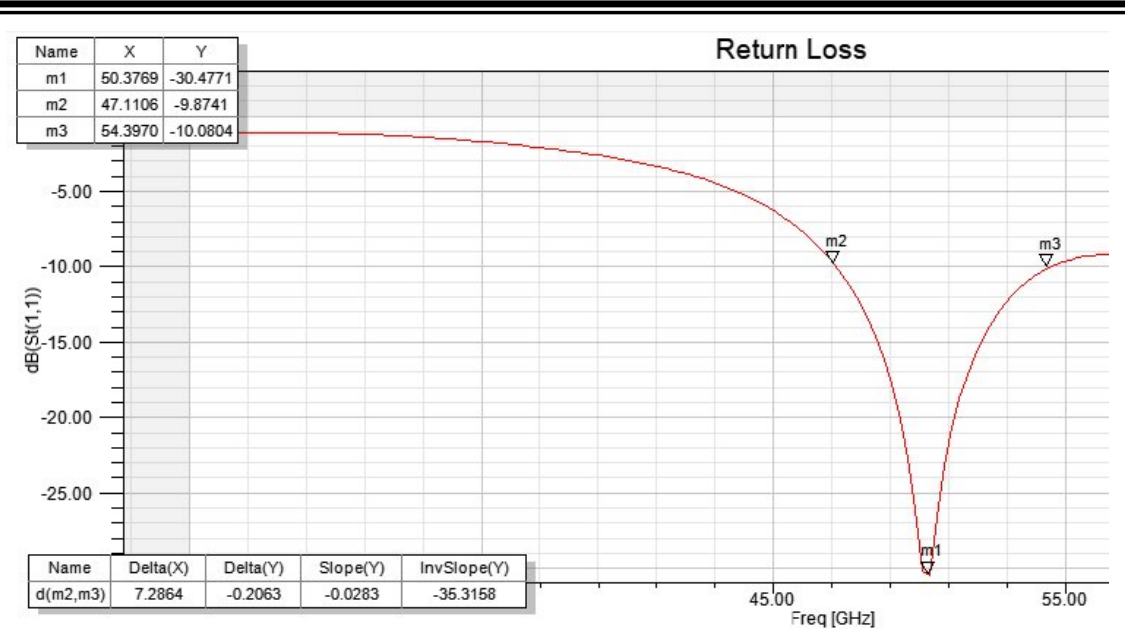

Figure 6 Return loss versus frequency of the proposed $50 \mathrm{GHz}$ antenna

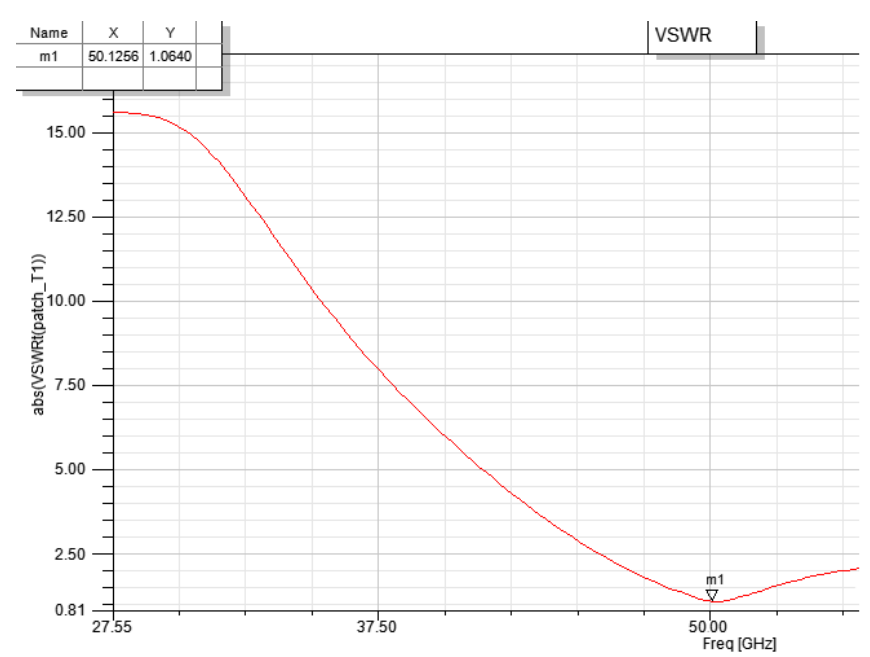

Fig. (7): VSWR versus frequency of the designed $50 \mathrm{GHz}$ antenna

\subsection{Comparison of the designed antennas with other designs in literature}

Table 2 presents numerous antenna designs for mmWave bands that reported in literature in comparison to the proposed antennas. The performance evaluation of the antennas in terms of bandwidth and maximum attainable gain has been studied. The type of the dielectric substrate with its thickness is also presented. Finally the suggested antenna configurations are also compared in order to study the complexity of the proposed designs.

It can be noticed the proposed antennas provide wider transmission bandwidth compared to other designs. For instance, the work presented in (Wang, Mu, Wang, Safavi-Naeini,
\& Liu, 2017) the bandwidth is $2.24 \mathrm{GHz}$ for a single-element antenna, and some improvement has been observed with 8-element array in spite of the system complexity. The $38 \mathrm{GHz}$ proposed antenna provides $8.06 \mathrm{dBi}$ of gain, which is better than all other single-element based designs. Although it is less than the $10 \mathrm{dBi}$ gain obtained using 8-element array in (Wang, Mu, Wang, Safavi-Naeini, \& Liu, 2017), also a maximum gain of $16.7 \mathrm{dBi}$ is achieved in (Rahayu, Fitria, Hakiki, \& Kurniawan, 2018) when an 8 -element configuration $(2 \times 4$ phased array) is used. In these cases the system complexity should be taken into consideration. With the exception of the work has been done in (Behera \& Barad, 2015), where FR-4 substrate

rawaz.abdullah@spu.edu.iq; kawan.ahmed@spu.edu.iq ${ }^{1}$ Corresponding author: Technical College of Engineering, Sulaimani Polytechnic University, 
with a $1.07 \mathrm{~mm}$ width has been used, in other papers a narrower dielectric substrate has been selected compared to the one used in this work which is RO4350B with $0.762 \mathrm{~mm}$ of width, with the advantage of transmission bandwidth and gain. These remarkable results ensure the designed antennas are reliable and further enhancement in transmission gain and bandwidth can be obtained if proposed designs are used in arrays.

Table (2): comparison of proposed microstrip antennas for mmWave bands

\begin{tabular}{|c|c|c|c|c|c|}
\hline Reference & $\begin{array}{c}\text { Bandwidth }(\mathrm{GHz}) / \\
\text { Operation Frequency } \\
\qquad(\mathrm{GHz})\end{array}$ & $\begin{array}{l}\text { Gain } \\
\text { (dBi) }\end{array}$ & $\begin{array}{l}\text { Substrate } \\
\text { Type }\end{array}$ & $\begin{array}{l}\text { Substrate } \\
\text { Thickness } \\
\text { (mm) }\end{array}$ & $\begin{array}{c}\text { Antenna } \\
\text { Configuration }\end{array}$ \\
\hline $\begin{array}{c}\text { (Bhadouria \& Kumar, } \\
\text { 2014) }\end{array}$ & $1.24 /(15.27-16.51)$ & 4.45 & FR-4 & 1.07 & $\begin{array}{l}\text { Single- } \\
\text { Element }\end{array}$ \\
\hline $\begin{array}{l}\text { (Haraz, Ashraf, \& } \\
\text { Alshebeili, 2015) }\end{array}$ & 0.810/(27.73-28.54) & 6.06 & Air & 0.314 & $\begin{array}{l}\text { Triple- } \\
\text { Element }\end{array}$ \\
\hline $\begin{array}{l}\text { (Aliakbari, Abdipour, } \\
\text { Mirzavand, Costanzo, } \\
\text { \& Mousavi, 2016) }\end{array}$ & $\begin{array}{c}0.850 /(29.25-30.1) \\
\& \\
0.750 /(36.25-37.0)\end{array}$ & $\begin{array}{c}4 \\
\& \\
4.5\end{array}$ & $\begin{array}{l}\text { RT/Duroid } \\
5880\end{array}$ & 0.254 & $\begin{array}{c}\text { Single-Element/Dual-B } \\
\text { and }\end{array}$ \\
\hline $\begin{array}{c}\text { (Wang, Mu, Wang, } \\
\text { Safavi-Naeini, \& Liu, } \\
\text { 2017) }\end{array}$ & $\begin{array}{c}2.24 /(33.88-36.12) \\
\& \\
3.85 /(32.5-36.35)\end{array}$ & $\begin{array}{c}7.93 \\
\& \\
10\end{array}$ & $\begin{array}{l}\text { RT/duroid58 } \\
80\end{array}$ & 0.5 & $\begin{array}{l}\text { Single-Element } \\
\qquad \& \\
\text { 8-Element Array }\end{array}$ \\
\hline $\begin{array}{l}\text { (Rahayu, Fitria, Hakiki, } \\
\text { \& Kurniawan, 2018) }\end{array}$ & $\begin{array}{c}1.219 /(28.114-29.333) \\
1.42 /(37.871-39.291) \\
\& \\
2.3 /(27-29.3) \\
1.5(37.8-39.3)\end{array}$ & $\begin{array}{c}6.934 \\
7.833 \\
\& \\
15.9 \\
16.7\end{array}$ & $\begin{array}{l}\text { RT/Duroid } \\
5880\end{array}$ & 0.254 & $\begin{array}{c}\text { Single-Element/Dual-B } \\
\text { and } \\
\& \\
\text { 2x4 Phased-Array/ } \\
\text { Dual-Band }\end{array}$ \\
\hline $\begin{array}{l}\text { Proposed } \\
38 \mathrm{GHz} \\
\text { Antenna }\end{array}$ & $4.01 /(35.23-39.24)$ & 8.06 & $\mathrm{RO} 4350 \mathrm{~B}$ & 0.762 & Single-Element \\
\hline $\begin{array}{l}\text { Proposed } \\
50 \mathrm{GHz} \\
\text { Antenna }\end{array}$ & $7.2864 /(47.1106-54.397)$ & 5.1 & $\mathrm{RO} 4350 \mathrm{~B}$ & 0.762 & Single-Element \\
\hline
\end{tabular}

\section{CONCLUSIONS}

In this work two separate microstrip antennas has been suggested for next generation systems to operate at the millimeter wave bands, for instance $38 \mathrm{GHz}$ and $50 \mathrm{GHz}$. At least $4 \mathrm{GHz}$ of bandwidth and 8 about $\mathrm{dBi}$ of gain are obtained with the $38 \mathrm{GHz}$ design. The $50 \mathrm{GHz}$ antenna provides a bandwidth of about $7.286 \mathrm{GHz}$ and a gain of $5.1 \mathrm{dBi}$. The RO4350B substrate is proposed to be used in both designs. Although the thickness of the indicated dielectric material is slightly wider compared to the previous related works, the proposed antennas have the advantages of wider bandwidth, higher gain, and simplicity.

Therefore, the proposed antennas could be used in future wireless applications and it can be easily fabricated, with satisfactory results in antenna gain, return loss, and VSWR as they have been proven by the simulation results using the widely used HFSS simulation software package. Further improvement in bandwidth and gain can be achieved if they are used

kawan.ahmed@spu.edu.iq

${ }^{1}$ Corresponding author: Technical College of Engineering, Sulaimani Polytechnic University,

Kurdistan Region, Iraq 
in arrays.

\section{REFERENCES}

-Ahmed, K. F., Abdullah, R. H., \& Abdalla, D. S. (2017, August). Design and Simulation of Microstrip Patch Antenna for Wireless Applications. Kurdistan Journal for Applied Research (KJAR), 2(3). Retrieved from kjar.spu.edu.iq

-Akhil, G., \& Rakesh, K. J. (2015, July 28). A Survey of 5G Network: Architecture and Emerging Technologies. IEEE Access, 3, 1206 - 1232. doi: 10.1109/ACCESS.2015.2461602

-Aliakbari, H., Abdipour, A., Mirzavand, R., Costanzo, A., \& Mousavi, P. (2016). A Single Feed Dual-band Circularly Polarized Millimeter-wave Antenna for 5G Communication. 2016 10th European Conference on Antennas and Propagation $(E u C A P)$ (pp. 1-5). Davos, Switzerland : IEEE. doi:10.1109/EuCAP.2016.7481318

-Balanis, C. A. (2005). Antenna Theory: Analysis and Design (3rd ed.). New Jersey, USA: Johm Wiley \& Sons.

-Behera, S., \& Barad, D. (2015). A Novel Design of Microstrip Fractal Antenna for Wireless Sensor Network. IEEE International Conference on Computation of Power, Energy Information and Communication (ICCPEIC), pp. (pp. 470 - 474). IEEE.

-Bhadouria, A. S., \& Kumar, M. (2014). Wide $\mathrm{Ku}-$ Band Microstrip Patch Antenna Using Defected patch and ground. IEEE International Conference on Advances in Engineering \& Technology Research (ICAETR-2014) (pp. 1-5). Unnao, India: IEEE. doi: 10.1109/ICAETR.2014.7012794
-Haraz, O. M., Ashraf, M., \& Alshebeili, S. (2015). Single-Band PIFA MIMO Antenna System Design for Future $5 \mathrm{G}$ Wireless Communication Applications. 11th IEEE International Conference on Wireless and Mobile Computing, Networking and Communications (WiMob) (pp. 608-612). IEEE.

-Kraus, J. D., \& Marhefka, R. J. (2002). Antennas for all applications (3rd ed.). NewYork: McGraw-Hill.

-Mishra, B., Singh, V., Singh, R. K., Singh, N., \& Singh, R. (2018, January ). A compact UWB patch antenna with defected ground for $\mathrm{Ku} / \mathrm{K}$ band applications. Microwave and Optical Technology Letters, 60(1), 1-6. doi:10.1002/mop.30911

-Rahayu, Y., Fitria, L., Hakiki, Y., \& Kurniawan, A. (2018). A New 2x4 Array Design of Dual-Band Millimeter-Wave Antenna for $5 \mathrm{G}$ Applications. 2018 International Workshop on Antenna Technology (iWAT) (pp. 1-4). Nanjing, China : IEEE. doi:10.1109/IWAT.2018.8379210

-Wang, Q., Mu, N., Wang, L., Safavi-Naeini, S., \& Liu, J. (2017, December 17). 5G MIMO Conformal Microstrip Antenna Design. Wireless Communications and Mobile Computing, 1-11. Retrieved from https://doi.org/10.1155/2017/7616825

-Zhouyue, P., \& Farooq, K. (2011, June 7). An introduction to millimeter-wave mobile broadband systems. IEEE Communications Magazine, $\quad$ 49(6), 101-107. doi:10.1109/MCOM.2011.5783993

rawaz.abdullah@spu.edu.iq; $\quad$ kawan.ahmed@spu.edu.iq ${ }^{1}$ Corresponding author: Technical College of Engineering, Sulaimani Polytechnic University, 